\title{
Facile synthesis of new divergent imidazole-containing ligands for a 1-D cobalt(II) coordination polymer
}

E Liu, ${ }^{a}$ Hangxing Xiong, ${ }^{\mathrm{a}}$ Li Li, ${ }^{\mathrm{a}}$ Chengxiong Yang, ${ }^{\mathrm{a}}$ Zhiwei Yin, ${ }^{\mathrm{b}}$ Anthony Chang, ${ }^{\mathrm{b}}$ David R. Manke, ${ }^{\mathrm{c}}$ James A. Golen ${ }^{\mathrm{c}}$ and Guoqi Zhang ${ }^{\mathrm{b} *}$

${ }^{a}$ College of Chemical Engineering and Pharmacy, Jingchu University of Technology, Jingmen 448000, China

${ }^{b}$ Department of Sciences, John Jay College and The Graduate Center, The City University of New York, New York, NY 10019, USA

${ }^{c}$ Department of Chemistry and Biochemistry, University of Massachusetts Dartmouth, North Dartmouth, MA 02747, USA.

${ }^{*}$ Corresponding author. Email address: guzhang@jjay.cuny.edu

Keywords: Divergent ligand; Imidazole; Cobalt(II); Crystal structure; Coordination polymer

\begin{abstract}
A new divergent ligand (3a) containing a triaryl core and two imidazole side-arms has been designed and synthesized. The synthetic procedure utilizes a two-step strategy, i.e. the Kröhnke condensation, followed by a $\mathrm{Cu}$-catalyzed Ullman-type coupling. This synthetic strategy allows the facile introduction of various substituents on the 4-position of the central pyridine in the ligands, which was proved by the synthesis of a ligand analog $(\mathbf{3 b})$. The new ligands were well characterized by spectroscopic methods and X-ray structural analysis was carried out for 3a. Reaction of 3a with $\mathrm{Co}(\mathrm{NCS})_{2}$ by a layering method afforded single crystals of a coordination polymer $\mathbf{5}$, which was structurally characterized by X-ray diffraction. 5 is composed of two ligands and one $\mathrm{Co}(\mathrm{NCS})_{2}$ in its asymmetric unit and features a 1-D coordination polymer with nano-scale metallomacrocyles. The structure of $\mathbf{5}$ is found to be quite different from all known coordination networks composed of $\mathrm{Co}(\mathrm{NCS})_{2}$ and closely related divergent ligands.
\end{abstract}

\section{Introduction}

In recent years, the divergent analogues of the classical tridentate 2,2':6',2'-terpyridine (2,2':6', 2"-tpy) derived ligands, 4,2':6',4"-tpy (1, Scheme 1) have become a popular choice for the construction of novel metal-organic coordination polymers or networks that displayed not only interesting supramolecular structures but also intriguing materials properties [1-6]. Generally, 4'-aryl-4,2':6',4"-tpys could be readily synthesized and purified in reasonable yields through 
the conventional one-pot Kröhnke condensation that has been employed for the preparation of a majority of 4'-aryl-2,2':6',2"-tpys [7]. A variety of transition metals (such as $\mathrm{Zn}^{\mathrm{II}}, \mathrm{Cd}^{\mathrm{II}}, \mathrm{Hg}^{\mathrm{II}}$, $\mathrm{Cu}^{\mathrm{II}}, \mathrm{Co}^{\mathrm{II}}$ and $\mathrm{Mn}^{\mathrm{II}}$ etc.) have been explored by the Constable, our and other groups through coordination-driven self-assembly to construct diverse metal-organic network structures [810], where the 4'-position substituent effect has been extensively studied, thanks to the easiness on ligand modification. Apparently, the divergent $\mathrm{N}$-donors in 4,2':6',4"-tpys open new opportunities for the formation of more complicated supramolecular structures upon coordinating to metal ions, in comparison with the chelating $\mathrm{N}_{3}$ cavity of 2,2':6',2"-tpys.

In search of other divergent ligand analogs to 4,2':6',4"-tpys, we found that 2,6bis(imidazole-1-yl)pyridine (2, Scheme 1) bearing $N$-imidazolyl side-arms instead of 4-pyridyl group could exhibit similarly interesting coordination chemistry, even though the V-shaped Ndonors in 2 adopt a smaller angle. In addition, rotations about the $\mathrm{C}-\mathrm{N}$ bonds between the pyridyl core and imidazolyl arms would lead to different ligand conformations during the process of metal-ligand self-assembly, whereas rotations about the inter-ring $\mathrm{C}-\mathrm{C}$ bond in 4 , $2^{\prime}: 6 ', 4 "$-tpy has no effect on the directionalities of the peripheral $\mathrm{N}$-donors. However, up to date there were only a few metal coordination networks based upon this ligand that have been reported [11], although it was recently revealed that this compound comprises of a perfect building block for the construction of various molecular boxes and covalent macrocycles [12]. Indeed, the difficulty in modifying the pyridine core with different substituents has largely limited its applications in coordination and supramolecular chemistry.

In continuation with our recent work on transition metal chemistry based on the flexible ligands, 4'-aryl-4,2':6',4'-tpys and other N-rich analogs $[9,13]$, we were interested in further modifying these ligands by varying the angle between the $\mathrm{V}$-shaped $\mathrm{N}$ coordination sites through the introduction of imidazolyl side-arms. We envisaged that one could construct the triaryl core similar to $4,2^{\prime}: 6^{\prime}, 4^{\prime \prime}$-tpy by taking advantage of the easiness of modification on the 4-position of central pyridine through one-pot Kröhnke condensation, and then imidazolyl units can be readily anchored on the para-position of the side phenyl rings, should halosubstituents were present in the phenyl rings of the starting materials. Therefore, we report herein the successful synthesis of a novel divergent ligand bearing imidazolyl side-arms with a larger distance being between the divergent N-donating sites (Scheme 1). It is revealed that the $\mathrm{R}$ substituents in the 4-position of the central pyridine core can be readily altered as we anticipated. The application of this type of ligands in the synthesis of metal-organic coordination polymers/networks has been demonstrated through the synthesis and X-ray 
structural characterization of a one-dimensional (1-D) cobalt(II) coordination polymer containing nano-scale metallomacrocyclic motifs.
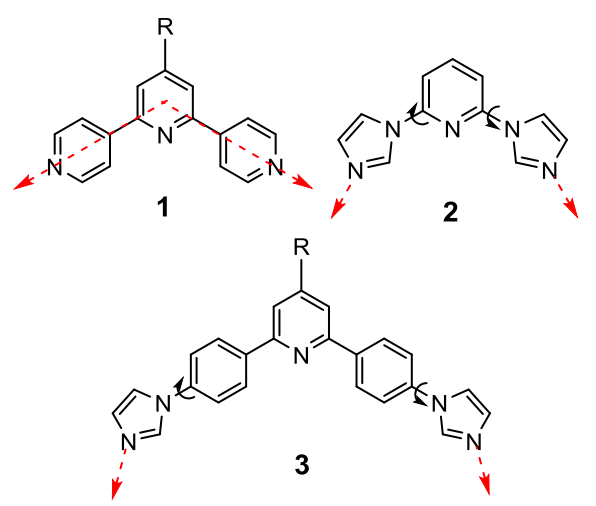

Scheme 1. Structures and various metal coordination directionalities of divergent ligands 1-3.

\section{Experimental}

\subsection{General}

Solvents and reagents were purchased from Fisher Scientific or Sigma-Aldrich in the US. All reactions were performed under ambient conditions (no inert atmosphere). FT-IR spectra were measured on a Shimadzu 8400S instrument with solid samples using a Golden Gate ATR accessory. Thermogravimetric analysis (TGA) was carried out on a Shimadzu TG-50 analyzer under $\mathrm{N}_{2}$ atmosphere with a heating rate of $20^{\circ} \mathrm{C} / \mathrm{min} .{ }^{1} \mathrm{H}$ and ${ }^{13} \mathrm{C} \mathrm{NMR}$ spectra were obtained at room temperature on a Bruker III $500 \mathrm{MHz}$ spectrometer with TMS as an internal standard. High resolution mass spectra were recorded on an Agilent 6550 iFunnel ESI-QTOF-LC/MS instrument. Elemental Analyses were performed by Midwest Microlab LLC in Indianapolis.

\subsection{Synthesis of $\mathbf{4 a}$}

In a $250 \mathrm{~mL}$ round-bottom flask equipped with a magnetic stirrer, 4-bromoacetophenone (3.94 g, 20.0 mmol) was added to a solution of benzaldehyde $(1.06 \mathrm{~g}, 10.0 \mathrm{mmol})$ in $\mathrm{EtOH}(80 \mathrm{~mL})$. $\mathrm{KOH}$ pellets $(0.84 \mathrm{~g}, 15 \mathrm{mmol})$ were then added, followed by aqueous $\mathrm{NH}_{3}(28 \%, 50 \mathrm{~mL})$. The resulting reaction mixture was heated to $70{ }^{\circ} \mathrm{C}$ upon rigorous stirring for 24 hours. The suspension was cooled to room temperature and filtered. Off-white solid was collected, washed with $\mathrm{EtOH}$ and dried in a desiccator over $\mathrm{P}_{2} \mathrm{O}_{5}$. Yield: $2.60 \mathrm{~g}(56 \%) .{ }^{1} \mathrm{H}$ NMR $\left(500 \mathrm{MHz}, \mathrm{CDCl}_{3}\right) \delta 8.10(\mathrm{~d}, J=8.0 \mathrm{~Hz}, 4 \mathrm{H}), 7.90(\mathrm{~s}, 2 \mathrm{H})$, $7.76(\mathrm{~d}, J=7.5 \mathrm{~Hz}, 2 \mathrm{H}), 7.68(\mathrm{~d}, J=8.5 \mathrm{~Hz}, 4 \mathrm{H}), 7.59-7.53(\mathrm{~m}, 3 \mathrm{H}) \mathrm{ppm} ;{ }^{13} \mathrm{C} \mathrm{NMR}(125 \mathrm{MHz}$, 
$\left.\mathrm{CDCl}_{3}\right) \delta 156.39,150.88,138.54,137.91,131.93,129.35,129.26,128.77,127.22,123.83,117.36$ ppm. HR-MS (ESI, positive): m/z 465.9621 [M + H $]^{+}$(the only peak, calc. 465.9629).

\subsection{Synthesis of $\mathbf{4 b}$}

4b was synthesized according to the same procedure as for $\mathbf{4 a}$, except the replacement of benzaldehyde with pyridine-4-carboxaldehyde (1.06 g, $10.0 \mathrm{mmol})$. Off-white solid of $4 \mathbf{b}$ was collected in $52 \%$ yield $(2.42 \mathrm{~g}) .{ }^{1} \mathrm{H}$ NMR $\left(500 \mathrm{MHz}, \mathrm{CDCl}_{3}\right) \delta 8.84(\mathrm{~s}, 2 \mathrm{H}), 8.09(\mathrm{~d}, J=8.5 \mathrm{~Hz}, 4 \mathrm{H})$, 7.90 (s, $2 \mathrm{H}), 7.69$ (m, $6 \mathrm{H}) \mathrm{ppm} ;{ }^{13} \mathrm{C} \mathrm{NMR}\left(125 \mathrm{MHz}, \mathrm{CDCl}_{3}\right) \delta 156.99,150.38,147.75,146.48$, 137.66, 132.04, 128.66, 124.12, 121.83, 116.74 ppm. Anal. Calcd. for $\mathrm{C}_{22} \mathrm{H}_{14} \mathrm{Br}_{2} \mathrm{~N}_{2}$ : C 56.68, H 3.03, N 6.01\%. Found C 56.59, H 3.01, N 6.18\%.

\subsection{Synthesis of $\mathbf{3 a}$}

To a $100 \mathrm{~mL}$ Pyrex tube was added a mixture of $4 \mathbf{a}(1.00 \mathrm{~g}, 2.16 \mathrm{mmol})$, imidazole $(2.94 \mathrm{~g}, 43.2$ $\mathrm{mmol}), \mathrm{Cu}_{2} \mathrm{O}(0.030 \mathrm{~g}, 0.2 \mathrm{mmol}), \mathrm{CuSO}_{4}(0.070 \mathrm{mg}, 0.2 \mathrm{mmol})$ and $\mathrm{K}_{2} \mathrm{CO}_{3}(3.00 \mathrm{~g}, 21.6 \mathrm{mmol})$ under Ar atmosphere, and then anhydrous DMF $(10 \mathrm{~mL})$ was added. The suspension was heated to reflux and stirred overnight. The reaction mixture was cooled to room temperature and filtered, the solid was washed with $\mathrm{CH}_{2} \mathrm{Cl}_{2}(10 \mathrm{~mL} \times 2)$. Water $(100 \mathrm{~mL})$ was added to the filtrate which was then extracted with $\mathrm{CH}_{2} \mathrm{Cl}_{2}(50 \mathrm{~mL} \times 2)$. The organic layer was collected and washed with water for three times. The solution was dried over anhydrous $\mathrm{Na}_{2} \mathrm{SO}_{4}$ and filtered. The solvent was removed under reduced pressure. The product was purified through a flash column chromatography (eluent: ethyl acetate/methanol $=1: 10, \mathrm{v} / \mathrm{v}$ ) to give a white solid. Colorless single crystals were obtained by slow evaporation of a $\mathrm{CH}_{2} \mathrm{Cl}_{2}-\mathrm{MeOH}$ of $\mathbf{3 a}$ at room temperature. Yield: $0.86 \mathrm{~g}(91 \%)$. FT-IR (solid, $\mathrm{cm}^{-1}$ ): $1610 \mathrm{~m}, 1548 \mathrm{w}, 1522 \mathrm{~s}, 1484 \mathrm{~s}, 1396 \mathrm{~m}, 1301 \mathrm{~s}, 1247 \mathrm{~s}, 1186 \mathrm{w}, 1110 \mathrm{w}, 1053 \mathrm{~s}, 961 \mathrm{w}, 901 \mathrm{w}, 817 \mathrm{~s}, 773 \mathrm{~s}$, 727m, 700m, 654s. ${ }^{1} \mathrm{H}$ NMR (400 MHz, $\left.\mathrm{CDCl}_{3}\right) \delta 8.34(\mathrm{~d}, J=6.0 \mathrm{~Hz}, 4 \mathrm{H}), 8.00$ (s, $\left.2 \mathrm{H}\right), 7.94$ (s, 2 $\mathrm{H}), 7.76(\mathrm{~d}, J=4.8 \mathrm{~Hz}, 2 \mathrm{H}), 7.58-7.52(\mathrm{~m}, 7 \mathrm{H}), 7.38(\mathrm{~s}, 2 \mathrm{H}), 7.27$ (s, $2 \mathrm{H}) \mathrm{ppm} ;{ }^{13} \mathrm{C}$ NMR $(100$ $\left.\mathrm{MHz}, \mathrm{CDCl}_{3}\right) \delta 156.22,150.84,138.60,138.59,137.90,135.50,130.46,139.36,129.36,129.28$, 128.66, 127.19, 121.52, 118.16, 117.40 ppm. HR-MS (ESI, positive): m/z $462.1692[\mathrm{M}+\mathrm{Na}]^{+}$(calc. 462.1695), 440.1873 [M + H] ${ }^{+}$(base peak, calc. 440.1875).

\subsection{Synthesis of $\mathbf{3 b}$}

$\mathbf{3 b}$ was prepared according to the same procedure as for $\mathbf{3 a}$, except the use of $\mathbf{4 b}(1.01 \mathrm{~g}, 2.16 \mathrm{mmol})$ as the precursor. 3b was isolated as white solid in $76 \%$ yield $(0.72 \mathrm{~g})$ after column chromatography. FT-IR (solid, $\mathrm{cm}^{-1}$ ): 1740m, 1592s, 1521s, 1484m, 1397m, 1302s, 1246m, 1112w, 1053s, 962m, 
902w, 825s, 727m, 654m, 622m. ${ }^{1} \mathrm{H}$ NMR (400 MHz, $\left.\mathrm{CDCl}_{3}\right) \delta 8.83(\mathrm{~d}, J=6.0 \mathrm{~Hz}, 2 \mathrm{H}), 8.35(\mathrm{~d}, J=$ $8.8 \mathrm{~Hz}, 4 \mathrm{H}), 7.99$ (s, $2 \mathrm{H}), 7.95$ (s, $2 \mathrm{H}), 7.68$ (d, J = 6.0 Hz, 2 H), 7.59 (d, J = 8.8 Hz, 4 H), 7.39 (s, 2 $\mathrm{H}), 7.27(\mathrm{~s}, 2 \mathrm{H}) \mathrm{ppm} ;{ }^{13} \mathrm{C} \mathrm{NMR}\left(100 \mathrm{MHz}, \mathrm{CDCl}_{3}\right) \delta 156.69,150.81,148.06,146.01,138.19$, 137.93, 135.51, 130.70, 128.68, 121.63, 121.51, 118.06, 116.94 ppm. HR-MS (ESI, positive): m/z 463.1664 $[\mathrm{M}+\mathrm{Na}]^{+}$(calc. 463.1647), 441.1828 $[\mathrm{M}+\mathrm{H}]^{+}$(base peak, calc. 441.1828).

\subsection{Synthesis of 5}

A solution of $3 \mathbf{a}(43.9 \mathrm{mg}, 0.100 \mathrm{mmol})$ dissolved in $\mathrm{MeOH} / \mathrm{CH}_{2} \mathrm{Cl}_{2}(10 \mathrm{~mL}, 1: 4$, v/v) was placed in a long test tube. A mixture of $\mathrm{MeOH}$ and $\mathrm{CH}_{2} \mathrm{Cl}_{2}(6 \mathrm{~mL}, 1: 1$, v/v) was then layered on the top of this solution, followed by another solution of $\mathrm{Co}(\mathrm{NCS})_{2}(17.5 \mathrm{mg}, 0.100 \mathrm{mmol})$ in $\mathrm{MeOH}(10 \mathrm{~mL})$. The tube was sealed and allowed to stand at room temperature for about 15 days, during which time X-ray quality pinkish crystals grew on the wall of the tube. After X-ray diffraction measurement crystals that were used for analysis were collected by decanting the solvent, washed with $\mathrm{MeOH}$ and dried in the air. The crystals became much paler after being moved out from the solution and exposure to air, due to the loss of interstitial solvents. Yield: $41.0 \mathrm{mg}$ (78\% based on 3a). FT-IR (solid, $\mathrm{cm}^{-1}$ ): 2063s, $1597 \mathrm{~m}, 1549 \mathrm{~m}, 1522 \mathrm{~s}, 1498 \mathrm{~m}, 1429 \mathrm{w}, 1302 \mathrm{~m}, 1244 \mathrm{~m}, 1122 \mathrm{w}, 1066 \mathrm{~s}, 964 \mathrm{~m}, 934 \mathrm{~m}, 833 \mathrm{~s}, 764 \mathrm{~s}$, 688w, 659m, 623w, 528m. Anal. Calcd. for $\mathrm{C}_{60} \mathrm{H}_{42} \mathrm{CoN}_{12} \mathrm{~S}_{2}$ : C 68.37, H 4.02, N $15.95 \%$; Found C 67.98, H 3.95, N $15.72 \%$.

\subsection{X-ray Structural Determinations}

Suitable single crystals were mounted on Cryoloops with oil. Data were collected for $\mathbf{3 a}$ and $\mathbf{5}$ with a Bruker APEX II CCD using Mo-K $\alpha$ radiation and a Bruker D8 Venture X-ray instrument using Cu$\mathrm{K} \alpha$ radiation, respectively. Data were corrected for absorption with SADABS and structures solved by direct methods. All non-hydrogen atoms were refined anisotropically by full-matrix least squares on $\mathrm{F}^{2}$. Hydrogen atoms for 3a were found from Fourier difference maps and refined isotropically. In the structure of $\mathbf{5}$, sulfur atoms S1 and S2 were disordered over two positions with occupancies 63.1/38.9 and 94.7/5.3\%, respectively. All hydrogen atoms were placed in calculated positions with appropriate riding parameters. Large solvent accessible voids were observed in the structure and the diffused solvent was assumed to be $\mathrm{CH}_{2} \mathrm{Cl}_{2}$ and was treated using the PLATON program SQUEEZE [14]. Crystal structures and packing figures were drawn with the program Mercury v. 2.4 [15]. The crystallographic refinement data are listed below.

3a: $\mathrm{C}_{29} \mathrm{H}_{21} \mathrm{~N}_{5}, M=439.51$, colorless block, monoclinic, space group $P 2 / \mathrm{n}, a=19.4272(5), b=$ 10.8084(3), $c=20.7906(5) \AA, \beta=100.8370(10), V=4287.69(19) \AA^{3}, Z=8, D_{c}=1.362 \mathrm{Mg} \mathrm{m}^{-3}$, 
$\mu(\mathrm{Mo}-\mathrm{K} \alpha)=0.650 \mathrm{~mm}^{-1}, T=120(2) \mathrm{K}$. Total 26982 reflections, 6923 unique. Refinement of 7840 reflections (617 parameters) with $I>2 \sigma(I)$ converged at final $R_{1}=0.0365\left(R_{1}\right.$ all data $\left.=0.0418\right), w R_{2}$ $=00908\left(w R_{2}\right.$ all data $\left.=0.0944\right), \mathrm{GOF}=1.037$.

5: $\mathrm{C}_{66} \mathrm{H}_{44} \mathrm{Cl}_{2} \mathrm{CoN}_{12} \mathrm{~S}_{2}, M=1139.03$, colorless plate, monoclinic, space group $P 2(1) / \mathrm{c}, a=18.7769(5)$, $b=22.0438(6), c=14.0169(4) \AA, \beta=96.7920(10), V=5761.1(3) \AA^{3}, Z=4, D_{c}=1.313 \mathrm{Mg} \mathrm{m}^{-3}$, $\mu(\mathrm{Mo}-\mathrm{K} \alpha)=4.264 \mathrm{~mm}^{-1}, T=120(2) \mathrm{K}$. Total 10504 reflections, 8376 unique. Refinement of 10504 reflections (684 parameters) with $I>2 \sigma(I)$ converged at final $R_{1}=0.0645\left(R_{1}\right.$ all data $\left.=0.0803\right), w R_{2}$ $=0.1636\left(w R_{2}\right.$ all data $\left.=0.1742\right), \mathrm{GOF}=1.016$.

\section{Results and Discussion}

\subsection{Ligand synthesis and characterization}

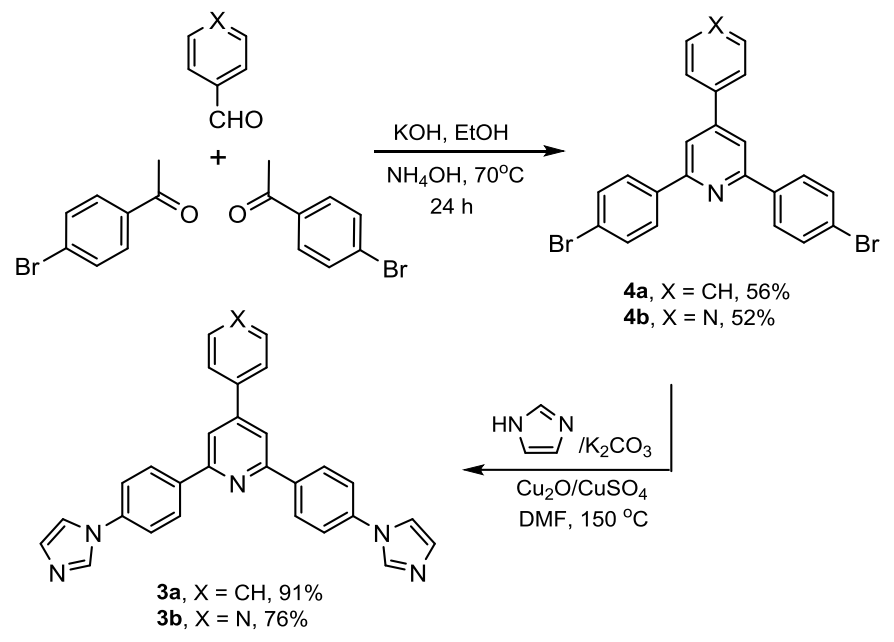

Scheme 2. The synthetic route to $\mathbf{3 a}$ and $\mathbf{3 b}$.

The synthesis of the divergent ligand (3a) was carried out in two steps (Scheme 2). Initially, we attempted to synthesize the dibromo-containing precursor $4 \mathbf{a}$ by employing the facile one-pot Kröhnke condensation as reported for tpy ligands [7-9]. However, the room-temperature reaction of benzaldehyde with two equivalent of 4'-bromoacetophenone in the presence of $\mathrm{KOH}$ followed by addition of excess aqueous $\mathrm{NH}_{3}$ did not provide the desired product after $24 \mathrm{~h}$, yet a chalcone compound as a major product was isolated as confirmed by NMR, resulting from the $1: 1$ condensation of 4'-bromoacetophenone and benzaldehyde. Elevating the reaction temperature to 70 ${ }^{\circ} \mathrm{C}$ was found to be crucial for the formation of product $\mathbf{4 a}$ in a yield $(56 \%)$ close to those for relevant $4,2^{\prime}: 6^{\prime}, 4^{\prime \prime}$-tpys. Thus, the white solid of $\mathbf{4 a}$ was readily isolated from the one-pot reaction after $24 \mathrm{~h}$ at 
$70{ }^{\circ} \mathrm{C}$ by filtration (Scheme 2), and its purity was established by ${ }^{1} \mathrm{H}$ and ${ }^{13} \mathrm{C}$ NMR spectroscopies, and high resolution mass spectrometry (HR-MS). Similarly, 4-pyridyl derived analog 4b was also prepared in $52 \%$ yield by following the same procedure, except the use of pyridine-4-carboxaldehyde as a starting material. This indicates that the modification on the 4-position of the central pyridine ring is feasible, opening opportunities for the facile introduction of various substituents.

In the next step, we utilize the di-bromo substituted precursors to prepare imidazole-containing ligands 3a through an Ullman-type $\mathrm{C}-\mathrm{N}$ bond coupling reaction. Although it was unsuccessful when a catalytic method (conditions: $\mathrm{CuI} / \mathrm{L}$-proline, $\mathrm{K}_{2} \mathrm{CO}_{3}$, DMSO, $90{ }^{\circ} \mathrm{C}$ ) used for the synthesis of $\mathbf{1}$ in the literature [12], we eventually observed that the use of $\mathrm{Cu}_{2} \mathrm{O} / \mathrm{CuSO}_{4}$ as a catalyst combined with $\mathrm{K}_{2} \mathrm{CO}_{3}$ in DMF at $150{ }^{\circ} \mathrm{C}$ was effective for the coupling between $4 \mathbf{a}$ and imidazole in high yields [16]. As a result, the desired ligand 3a was obtained in $91 \%$ yield after purification by column chromatography (Scheme 2). Likewise, the derivative 3b containing an additional 4-pyridyl group was synthesized in $76 \%$ yield by using the same procedure. Both $\mathbf{3 a}$ and $\mathbf{3 b}$ are well soluble in $\mathrm{CH}_{2} \mathrm{Cl}_{2}, \mathrm{CHCl}_{3}$, DMF and DMSO, yet poorly soluble in $\mathrm{MeOH}$, acetone and acetonitrile. They were fully characterized by FT-IR, ${ }^{1} \mathrm{H}$ and ${ }^{13} \mathrm{C}$ NMR spectroscopies, and HR-MS. Mass spectrum of 3a displays peak envelops at $\mathrm{m} / \mathrm{z} 462.1692$ and 440.1873 , corresponding to the species $[\mathrm{M}+\mathrm{Na}]^{+}$and $[\mathrm{M}$ $+\mathrm{H}]^{+}$, respectively, which matched with those calculated and whose isotope modes are consistent with that simulated as well. Similar results were also observed in the mass spectrum of $\mathbf{3 b}$. The ${ }^{1} \mathrm{H}$ and ${ }^{13} \mathrm{C}$ NMR spectra of $\mathbf{3 a}$ and $\mathbf{3 b}$ recorded in $\mathrm{CDCl}_{3}$ reveal signals in agreement with their molecular structures as illustrated in Scheme 1. In addition, the crystal structure of $\mathbf{3 a}$ was confirmed by X-ray diffraction analysis.

\subsection{Crystal Structure of $\mathbf{3 a}$}

Colorless plates of $\mathbf{3 a}$ were grown by slow evaporation of a $\mathrm{CH}_{2} \mathrm{Cl}_{2}-\mathrm{MeOH}$ solution within three days. $\mathrm{X}$-ray structural analysis reveals that $\mathbf{3 a}$ crystallizes in the monoclinic space group $P 2 / \mathrm{n}$. An ORTEP representation of one molecule of $\mathbf{3 a}$ is shown in Fig. 1a. There exists one independent molecule of $\mathbf{3 a}$ in the asymmetric unit. Due to the flexibility of bonds between the phenyl and imidazolyl rings, molecule 3a in the solid state adopts a $\mathrm{C}_{1}$-symmetry and the two imidazole side-arms are twisted about the $\mathrm{C}-\mathrm{N}$ bond wtih different orientations, unlike the situations often observed in ligands and coordination complexes containing 2,2':6',2"- or 4,2':6',4"-tpy moiety, where the tpy domains are usually of $\mathrm{C}_{2}$-symmetry. The bond lengths in structure 3a are unexceptional. All peripheral rings are out of the plane of the central pyridine ring because of bond twisting. The dihedral angles between the phenyl rings (containing $\mathrm{C} 7, \mathrm{C} 14$ and $\mathrm{C} 24$ ) and pyridine ring are 23.71, 43.79 and 25.16 ${ }^{\circ}$, 
respectively, while those between the imidazolyl rings (N2 and N4) and adjacent phenyl ring are 30.37 and $40.23^{\circ}$, respectively. Due to the severe twisting of the aromatic rings through the correspondent $\mathrm{C}-\mathrm{C}$ bonds out of the central plane in the molecule of $\mathbf{3 a}$, the intermolecular packing as revealed in Fig. $1 \mathrm{~b}$ shows only very weak $\pi$... $\pi$ stacking interaction (the shortest intermolecular C...C distance is more than $3.8 \AA$ ), and the molecules in the asymmetric unit reside in four different orientations.

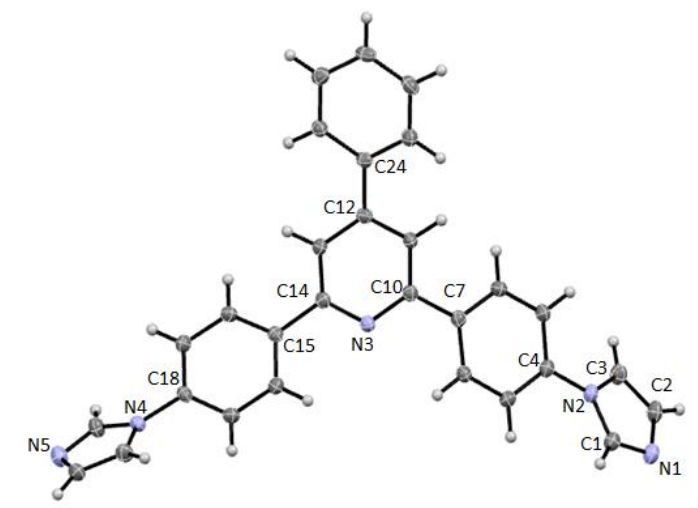

(a)

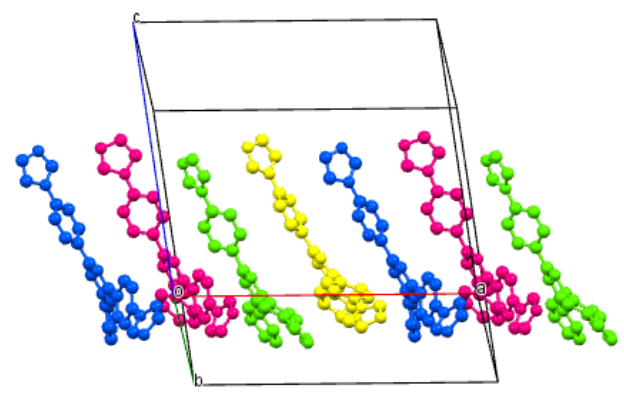

(b)

Fig. 1. (a) The ORTEP representation of molecule of 3a in the crystals with thermal ellipsoids plotted at the $50 \%$ probability level. (b) The molecular packing along the crystallographic $a$ axis in the unit cell of 3a.

\subsection{Synthesis and crystal structure of 5}

To examine the ability of the new divergent ligand 3a in forming coordination polymers or networks while reacting with metal ions, we conducted the reaction by choosing $\mathrm{Co}(\mathrm{NCS})_{2}$ as a precursor, as it has been often utilized for the construction of 2-D or 3-D frameworks involving 4'-substituted 4,2':6', $4 "$-tpys [8d, 8e, 17]. A layering method that was previously applied to grow crystals of coordination polymers with related ligands has been used for the reaction between 3a and Co(NCS $)_{2}$. Thus, carefully layering a solution of $\mathrm{Co}(\mathrm{NCS})_{2}$ onto the top of a solution of $\mathbf{3 a}$ in a $\mathrm{CH}_{2} \mathrm{Cl}_{2}-\mathrm{MeOH}$ solution with a metal-ligand ratio of $1: 1$ in a test tube, separated with a blank $\mathrm{CH}_{2} \mathrm{Cl}_{2}-\mathrm{MeOH}$ middle layer, 
led to good quality pinkish crystals of $\mathbf{5}$ after two weeks. However, when the same method was employed for the reaction of $\mathbf{3 b}$ with $\mathrm{Co}(\mathrm{NCS})_{2}$, no suitable crystals were harvested, although the tridentate ligand $\mathbf{3 b}$ could be attractive in generating novel porous framework [8c]. The bulk sample of 5 was characterized by IR spectrum and elemental analysis, and structurally analysed by X-ray crystallography. The IR spectrum reveals a characteristic strong absorption at $2063 \mathrm{~cm}^{-1}$, indicating the presence of NCS group. The elemental analysis data is in good agreement with the formation of a $1: 2$ Co-ligand complex. X-ray structural analysis clearly confirmed the formation of a coordination polymer, although the existence of disordered solvent molecules in the unit cell that have been treated using the PLATON program SQUEEZE [15]. 5 crystallizes in the monoclinic space group $P 2(1) / c$ and in the asymmetric unit there contains two independent ligand molecules and one cobalt(II) coordination sphere surrounded with two NCS groups. The ORTEP structure of two repeating structural units is presented in Fig. 2a. The cobalt center is hexa-coordinate with six nitrogen atoms, of which four are from distinct 3a molecules and two from NCS anions (each S atom is disordered over two positions, see experimental section), adopting an octahedral geometry. As expected, 3a behaves as a bidentate ligand to bind to the metal center with its two imidazolyl-N atoms, remaining the central pyridine uncoordinated. This is reminiscent of the coordination mode of 4,2':6',4"-tpys in all coordination structures thus far reported [5, 6, 8-10]. All bond angles and lengths around the $\mathrm{Co}^{\mathrm{II}}$ center are unexceptional and close to those in known Co(NCS $)_{2}$ networks of 4,2':6',4"-tpys [8d, 8e, 17]. The phenyl rings in the ligand are less twisted than those found in the structure of free ligand. The corresponding dihedral angles fall into the ranges of $3.19-20.97^{\circ}$ and $2.53-24.39^{\circ}$ with respect to the central pyridine ring, for two independent ligand molecules, respectively, whilst those between the imidazolyl rings and adjacent phenyl ring are 30.83 and $43.42^{\circ}$, which are still close to that observed in the free ligand. Interestingly, two centrosymmetrical ligands bridge two cobalt(II) centers $(\mathrm{Co} 1$ and $\mathrm{Co} 1 \mathrm{~A})$ to form a $[2+2]$ metallomacrocyclic subunit. In the macrocycle, the distance between metal centers is approximately $15.58 \AA$, while the distance between central pyridyl-N atoms of two ligands is about $12.10 \AA$, indicating the size of the macrocyle is in a nano-scale. Furthermore, the macrocyclic motifs are extended through the metal nodes to form a 1-D polymeric chain (Fig. 2b). Significant inter-chain $\pi$-stacking interactions were observed and serve to expand the chains to a 2-D sheet (Fig. 2c). Specifically, the $\pi$-stacking occurs between the central pyridine rings of adjacent 1-D chains in a head-to-tail manner, and the closest inter-atomic distance for the $\pi \ldots \pi$ packing is approximately $3.402 \AA$. The 2-D sheets are further packed layer-by-layer through additional $\pi$ stacking interactions of aromatic regions in the ligands to form a 3-D framework. 


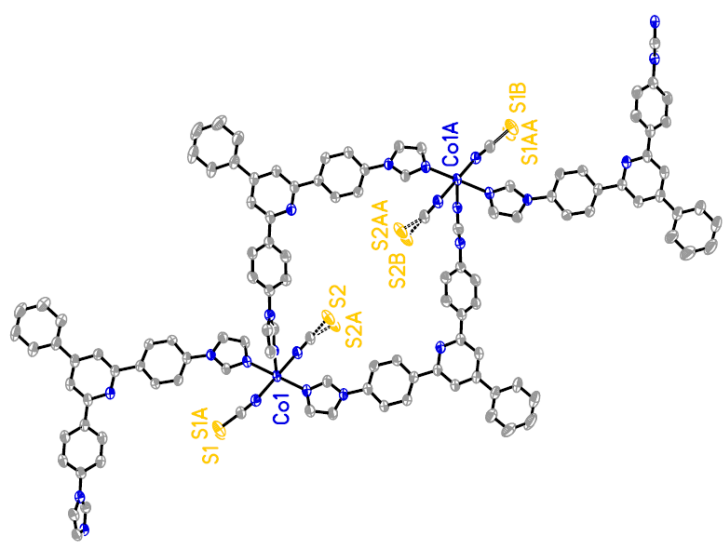

(a)

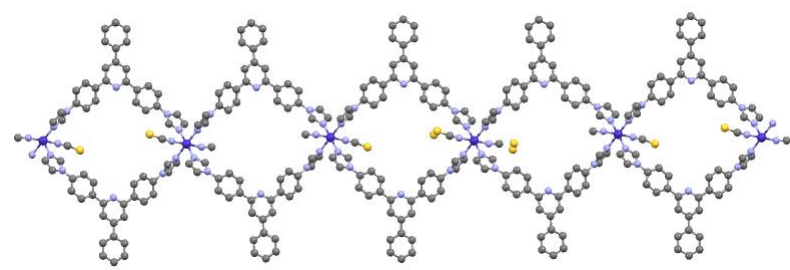

(b)

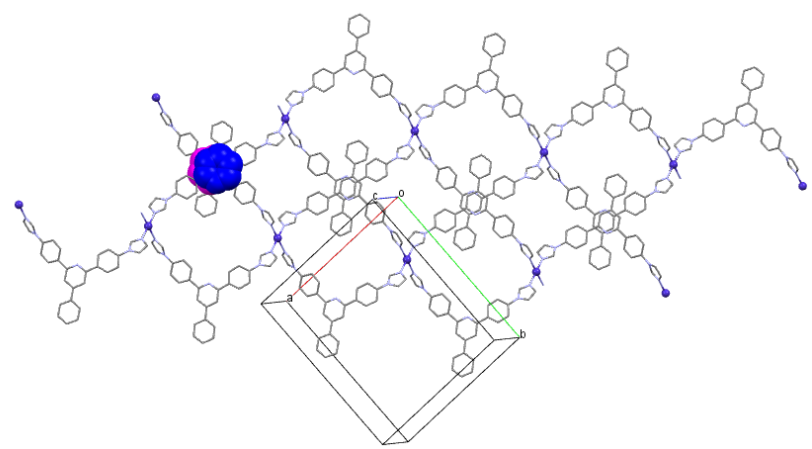

(c)

Fig. 2. (a) ORTEP structure of the repeat unit in $\mathbf{5}$ with thermal ellipsoids plotted at the $50 \%$ probability level. $\mathrm{H}$ atoms are omitted for clarity. (b) One of the 1-D polymeric chains found in 5. (c) The packing mode between 1-D chains in $\mathbf{5}$ showing the inter-hain $\pi$-stacking interactions between central pyridine rings as space-filling balls in pink and blue, respectively. NCS groups and $\mathrm{H}$ atoms are omitted for clarity.

A comparison of the structure of 5 revealed here with previously reported $\mathrm{Co}(\mathrm{NCS})_{2}$ networks based on structurally related ligands $\mathbf{1}$ and $\mathbf{2}$ is instructive. First, in 2003 Chung's group reported the reaction of $\mathrm{Co}(\mathrm{NCS})_{2}$ with 2 in a $\mathrm{MeOH}-\mathrm{H}_{2} \mathrm{O}$ system by the layering method and the resultant product was characterized as a 2-D coordination polymer (6) containing interesting cylindrical channels (Fig. 3a) [11a]. Our independent experiment using the same reaction procedure as for $\mathbf{5}$ (in $\mathrm{CH}_{2} \mathrm{Cl}_{2}-\mathrm{MeOH}$ ) also led to single crystals with a structure identical to the reported one [11a]. Although the coordination environments around $\mathrm{Co}^{\mathrm{II}}$ in $\mathbf{5}$ and $\mathbf{6}$ are similar, the linking modes of ligands are 
essentially different and as a result, distinct coordination networks (1-D vs. 2-D) were obtained. We propose that the strong $\pi$-stacking interactions between large aromatic regions are the driving forces for the formation of simple 1-D looped chain in $\mathbf{5}$. Next, a coordination polymer built from $\mathrm{Co}(\mathrm{NCS})_{2}$ and 4'-phenyl-4,2':6',4"-tpy (a derivative of $\mathbf{1}$ ) has also been reported by Constable and coworkers, where a 2-D network containing [4 4] metallomacrocycles was disclosed and significant $\pi$-stacking interactions of aromatic regions were observed between the 2-D networks. In addition, different 2-D or 3-D network structures were reported for cobalt(II) complexes with other 4'-aryl-4,2':6',4"-tpys $[8 \mathrm{e}, 17]$ and 4'-tert-butyl-4,2':6',4"-tpy [8d], yet none has revealed a structure found in $\mathbf{5}$.

The thermogravimetric analysis (TGA) of $\mathbf{5}$ under $\mathrm{N}_{2}$ atmosphere (Fig. 4) reveals that $\mathbf{5}$ is stable up to $345{ }^{\circ} \mathrm{C}$ and then experiences stepwise decomposition of the framework until over $800{ }^{\circ} \mathrm{C}$. In contrast, the 2-D network 6 was only stable up to $256^{\circ} \mathrm{C}$ as reported [11a].

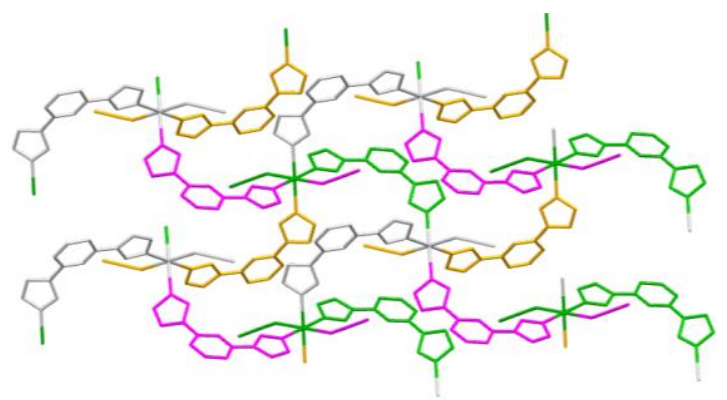

(a)

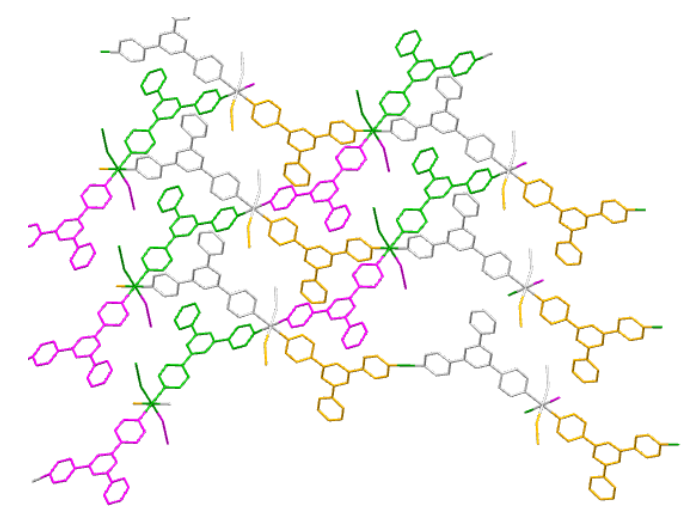

(b)

Fig. 3. The 2-D cobalt(II) networks assembled from $\mathrm{Co}(\mathrm{NCS})_{2}$ with 2 (a) [11a] and 4'-phenyl-4,2':6',4"-tpy (b) [CCDC No.856247, 8e]. The structures were regenerated based upon symmetry operations. 


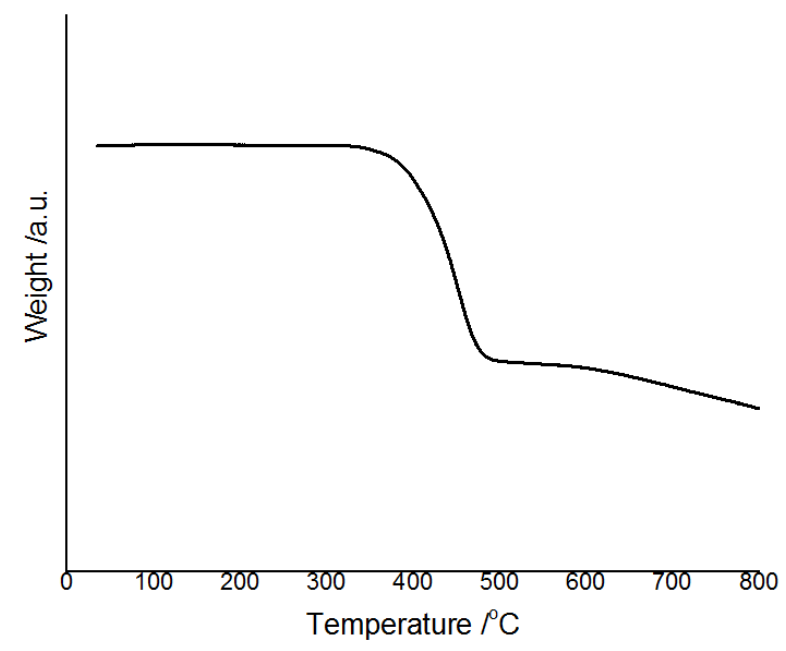

Fig. 4. The TG curve for 5 .

\section{Conclusion}

In summary, we have designed a new class of divergent nitrogen ligands containing two imidazolyl side-arms and synthesized two such derivatives in good yields through a facile two-step strategy which allows for easy modifications in the ligand backbone. A proof of principle for the utilization of the new ligands to prepare novel metal-organic coordination polymers has been carried out through the self-assembly of one of the ligands with $\mathrm{Co}(\mathrm{NCS})_{2}$. X-ray structural analysis of the resultant coordination polymer reveals a 1-D chain composed of nano-scale [2+2] metallomacrocycles, which is, however, essentially different from the known coordination networks of $\mathrm{Co}(\mathrm{NCS})_{2}$ with structurally related ligands. The extended aromatic domain in the new ligand should be responsible for the structural difference observed here upon coordinating to cobalt(II) ions. This work opens opportunities for the synthesis of a variety of divergent bis-imidazole-based ligands with different substituents, as well as the construction of novel metal-organic coordination polymers with these ligands.

\section{Acknowledgements}

We are grateful to a PSC-CUNY award (69069-0047), A "Seed Grant" from the Office for Advanced Research at John Jay College and the Program for Research Initiatives for Science Majors (PRISM) funded by the Title V, HSI-STEM and MSEIP programs within the U.S. Department of Education; the PAESMEM program through the National Science Foundation; and New York State's Graduate Research and Teaching Initiative. The National Science Foundation (CHE-1429086) is acknowledged 
for the X-ray diffractometer. The Natural Science Foundation of Hubei Province in China (2015CFA130 and 2013CFA015) is also acknowledged for partial support.

\section{Appendix A. Supplementary data}

Crystallographic data for the structural analysis have been deposited with the Cambridge Crystallographic Data Centre as supplementary publication. CCDC Nos. 1523763 and 1523764 contain the supplementary Crystallographic data for this paper. These data can be obtained free of charge via http://www.ccdc.cam.ac.uk/conts/retrieving.html (or from the Cambridge Crystallographic Data Centre, 12 Union Road, Cambridge CB2 1EZ, UK; fax: (+44) 1223-336-033; or e-mail: deposit@ccdc.cam.ac.uk).

\section{References}

[1] M. Barquín, J. Cancela, M.J. González Garmendia, J. Quintanilla, U. Amador, Polyhedron, 17 (1998) 2373

[2] (a) E.C. Constable, Chem. Soc. Rev. 36 (2007) 246;

(b) D.A. Safin, J.M. Frost, M. Murugesu, Dalton Trans. 44 (2015) 20287;

(c) E.C. Constable, C.E. Housecroft, New J. Chem. 22 (1998) 193.

[3] M. Barquín, J. Cancela, M. González, J. Garmendia, J. Quintanilla, U. Amador, Polyhedron 1998, 17, 2373.

[4] G.W.V. Cave, C.L. Raston, J. Supramol. Chem. 2002, 2, 317.

[5] C.E. Housecroft, Dalton Trans. 436 (2014) 594;

[6] C.E. Housecroft, CrystEngComm 17 (2015) 7461.

[7] F. Kröhnke, Synthesis (1976) 1.

[8] (a) E.C. Constable, G. Zhang, C.E. Housecroft, M. Neuburger, J.A. Zampese, CrystEngComm 11 (2009) 2279;

(b) E.C. Constable, G. Zhang, E. Coronado, C.E. Housecroft, M. Neuburger CrystEngComm 12 (2010) 2139;

(c) E.C. Constable, G. Zhang, C.E. Housecroft, J.A. Zampese, CrystEngComm 13 (2011) 6864;

(d) E.C. Constable, C.E. Housecroft, P. Kopecky, M. Neuburger, J.A. Zampese, G. Zhang, CrystEngComm 14 (2012) 446;

(e) E.C. Constable, C.E. Housecroft, M. Neuburger, S. Vujovic, J.A. Zampese, G. Zhang, CrystEngComm 14 (2012) 3554;

(f) Y.M. Klein, E.C. Constable, C.E. Housecroft and J.A. Zampese, Polyhedron 81 (2014) 98;

(g) E.C. Constable, C.E. Housecroft, S. Vujovic, J.A. Zampese, CrystEngComm 16 (2014) 328;

(h) Y.M. Klein, A. Prescimone, E.C. Constable, C.E. Housecroft, CrystEngComm 17 (2015) 6483.

[9] (a) G. Zhang, Y. Jia, W. Chen, W. F. Lo, N. Brathwaite, J.A. Golen, A.L. Rheingold, RSC Adv. 5

(2015) 15870; 
(b) Z. Yin, S. Zhang, S. Zheng, J.A. Golen, A.L. Rheingold, G. Zhang, Polyhedron 101 (2015) 139;

(c) G. Zhang, Y. Jia, T. Phoenix, D.R. Manke, J.A. Golen, A.L. Rheingold, RSC Adv. 6 (2016) 9270;

(d) L. Li, Y.Z. Zhang, E. Liu, C. Yang, J.A. Golen, G. Zhang, Polyhedron 105 (2016) 115.

[10] (a) F. Yuan, X. Wang, H.-M. Hu, S.-S. Shen, R. An, G.-L. Xue, Inorg. Chem. Commun. 48 (2014) 26;

(b) X.-L. Yang, Y.-Q. Shangguan, H.-M. Hu, B. Xu, B.-C. wang, J. Xie, F. Yuan, M. -L. Yang, F.-X. Dong, G.-L. Xue, L. J. Sol. State Chem. 216 (2014) 13;

(c) B. Xu, J. Xie, H.-M. Hu, X.-L. Yang, F.-X. Dong, M.-L. Yang, G.-L. Xue, Cryst. Growth Des. 14 (2014) 1629;

(d) P. Yang, M.-S. Wang, J.-J. Shen, M.-X. Li, Z.-X. Wang, M. Shao and X. He, Dalton Trans. 43 (2014) 1460 ;

(e) M.-S. Wang, M.-X. Li, X. He, M. Shao and Z.-X. Wang, Inorg. Chem. Commun. 42 (2014) 38.

[11] (a) S.U. Son, K.H. Park, B.Y. Kim, Y.K. Chung, Cryst. Growth Des. 3 (2003) 507;

(b) C.Y. Chen, P.Y. Cheng, H.H. Wu, H.M. Lee, Inorg. Chem. 46 (2007) 5691;

(c) J.Y. Lee, C.Y. Chen, H.M. Lee, E. Passaglia, F. Vizza, W. Oberhauser, Cryst. Growth Des. 11 (2011) 1230;

(d) J.Y. Lee, J.Y. Lee, H.M. Lee, Inorg. Chem. Commun. 52 (2015) 16;

(e) S. Tripathi, R. Srirambalaji, S. Patra, G. Anantharaman, CrystEngComm 17 (2015) 8876;

(f) S. Tripathi, S.K. Sachan, G. Anantharaman, Polyhedron 119 (2016) 55;

(g) J. Zhang, L. Gong, Y. Wang, J. Wu, J. Feng, C. Zhang, Polyhedron 123 (2016) 62.

[12] (a) H.-Y. Gong, B.M. Rambo, E. Karnas, V.M. Lynch, J. L. Sessler, Nat. Chem. 2 (2010) 406;

(b) H.-Y. Gong, B.M. Rambo, E. Karnas, V.M. Lynch, K. M. Keller, J. L. Sessler, J. Am. Chem. Soc. 133 (2011) 1526.

[13] (a) G. Zhang, J. Tan, Y.Z. Zhang, C. Ta, S. Sanchez, S.-Y. Cheng, J.A. Golen, A.L. Rheingold, Inorg. Chim. Acta 435 (2015) 147;

(b) G. Zhang, E. Liu, C. Yang, L. Li, J.A. Golen, A.L. Rheingold, Eur. J. Inorg. Chem. (2015) 939;

(c) Z. Yin, G. Zhang, S. Zheng, T. Phoenix, J.C. Fettinger, RSC Adv. 5 (2015) 36156;

(d) L.Li, Y.Z. Zhang, C. Yang, E. Liu, J. C. Fettinger, G. Zhang, J. Mol. Struct. 1110 (2016) 19.

[14] Mercury: Visualization and analysis of crystal structures. C.F. Macrae, P.R. Edgington, P. McCabe, E.

Pidcock, G.P. Shields, R. Taylor, M. Towler, J. van de Streek, J. Appl. Crystallogr. 39 (2006) 453.

[15] A.L. Spek, Acta Crystallogr., Sect. D: Biol. Crystallogr. 65 (2009) 148.

[16] M.-D. Zhang, Z.-Q. Shi, M.-D. Chen, H.-G. Zheng, Dalton Trans., 44 (2015) 5818.

[17] Y.M. Klein, A. Prescimone, E.C. Constable, C.E. Housecroft, Polyhedron, 103 (2016) 58. 